\title{
Methodology of physical exercise: A proposal and reliability of a questionnaire for fitness professionals
}

Authors' Contribution: A Study Design B Data Collection C Statistical Analysis D Data Interpretation E Manuscript Preparation F Literature Search G Funds Collection

\section{Francys Paula Cantieri ${ }^{1 \text { ABCDEF }}$, Antonio Carlos Gomes ${ }^{2}$ ADEF, Gustavo Aires de Arruda ${ }^{3}$ ABCDE,} Diogo Henrique Constantino Coledam ${ }^{4}$ BCDE, Edineia Aparecida Gomes Ribeiro ${ }^{5}$ CDEF, Mauro Virgilio Gomes de Barros ${ }^{3}$ CDEF, Ágata Cristina Marques Aranha6 ACDEF

${ }^{1}$ National Postdoctoral Program of Capes (PNPD) with incentive from FACEPE, School of Physical Education, University of Pernambuco, Recife, PE, Brazil

${ }^{2}$ Brazilian Olympic Institute, São Paulo, SP, Brazil

${ }^{3}$ School of Physical Education, University of Pernambuco, Recife, PE, Brazil

${ }^{4}$ Federal Institute of Education, Science and Technology of São Paulo, Boituva SP, Brazil

${ }^{5}$ Federal University of Mato Grosso do Sul, University City, Campo Grosso, Mato Grosso do Sul, Brazil

${ }^{6}$ Trás-dos-Montes and Alto Douro University, Vila Real, Portugal

\section{abstract}

Background:

Material and methods:

Results: The Cronbach's Alpha value was $0.78(95 \% \mathrm{Cl}: 0.70-0.83)$. The mean value of Cramer's $\vee$ was 0.16 $( \pm 0.06)$. Test-retest reliability values ranged from fair to good, with percentage agreement ranging from $48.8 \%$ (95\% Cl: $37.8-59.8)$ to $90.3 \%$ (95\% Cl: 81.3-95.4).

Conclusions: The questionnaire serves the purpose for which it was created and can be applied to identify how professionals structure their practices.

Key words: biomechanics; physical performance; countermovement jump; sprint; jumping ability.

\section{article details}

Article statistics:

Full-text PDF:

Copyright

Indexation:

Conflict of interests:

Corresponding author:

Open Access License:
Word count: 2224; Tables: 3; Figures: 0; References: 27

Received: October 2020; Accepted: June 2021; Published: December 2021

http://www.balticsportscience.com

(c) Gdansk University of Physical Education and Sport, Poland

Celdes, Clarivate Analytics Emerging Sources Citation Index (ESCI), CNKI Scholar (China National Knowledge Infrastructure), CNPIEC, DOAJ, EBSCO - Central \& Eastern European Academic Source, EBSCO - SPORTDiscus, EBSCO Discovery Service, Google Scholar, Index Copernicus, J-Gate, Naviga (Softweco, Primo Central (ExLibris), ProQuest - Family Health, ProQuest - Health \& Medical Complete, ProQuest - Illustrata: Health Sciences, ProQuest Nursing \& Allied Health Source, Summon (Serials Solutions/ProQuest, TDOne (TDNet), Ulrich's Periodicals Directory/ ulrichsweb, WorldCat (OCLC)

This research received no specific grant from any funding agency in the public, commercial, or not-for-profit sectors. Authors have declared that no competing interest exists.

Francys Paula Cantieri, Rua Olavo Bilac, 72, ap 1204, cep 51021480, Recife, PE, Brazil; e-mail: francyspaulapersonal@gmail.com; phone number: +55 (81) 999156299

This is an open access article distributed under the terms of the Creative Commons Attribution-Non-Commercial-NoDerivatives 4.0 International (https://creativecommons.org/licenses/by-nc-nd/4.0/), which permits use, distribution, and reproduction in any medium, provided the original work is properly cited, the use is non-commercial and is otherwise in compliance with the license. 


\section{INTRODUCTION}

Organizing guidelines for the prescription of physical exercise has received considerable attention among researchers in the field of sport and exercise science, due to the relationship between an inactive lifestyle and cardiovascular risk factors, chronic diseases, and mortality, among others [1, 2]. Studies have demonstrated a high prevalence of insufficient physical activity practice and high sedentary behavior $[3,4]$.

In this context, the practice of physical exercise is presented as an effective means to maintain or improve health conditions. In addition, guided activities seem to provide additional benefits compared to unsupervised activities [5].

Evidence considers the importance of controlling other aspects, such as frequency and intensity, for an exercise program to be successful [6,7]. Knowledge of the methodology used by fitness professionals to prescribe physical exercises is relevant as it allows analysis of the adequacy of this methodology, considering the general principles of physical training and the public served [5]. Understanding this issue contributes to reformulation of the curriculum of higher education courses, as well as directing the development of public policies and clinical practices regarding the methodology of physical exercise [8].

Although the current guidelines [5,9] provide information regarding prescription of exercise, to the best of our knowledge, there is no instrument aimed at assessing the methodology used by physical education teachers. Thus, the current study aimed to verify the psychometric properties of a questionnaire on the methodology applied by fitness professionals.

\section{METHODS}

\section{STUDY DESIGN}

In total, 333 professionals from postgraduate courses took part in the study, registered with the Federal Council of Physical Education, resident in the capital of the state of São Paulo and Londrina, city of the state of Paraná, Brazil. The participants' mean (standard deviation) age and years of professional experience were 32.2 (7.4) years and 6.4 (6.5) years, respectively.

The elaboration of the instrument followed the stages. In step I, the following databases were searched to identify existing instruments for this purpose: PubMed, Scielo, Lilacs, Scielo, Web of Science, and SportDiscus, with the following keywords combined: prescription of exercises, exercise training methodology, prescribing exercise, knowledge and physical training guidance, questionnaires, and training guidelines.

In step II, the questionnaire was structured with objective questions considering aspects related to exercise training methodology and exercise training structure (60 questions). In stage III, pre-testing $(\mathrm{n}=30)$ was carried out in order to assess the coherence between proposed questions and answers, in addition to seeking to identify out-of-context or misinterpreted questions, the way of filling in the alternatives (if there were questions without answer, answered with numbers, or with more than one marked alternative), the percentage of answers "I prefer not to answer", and the average time used to complete the instrument. The participants were asked to indicate any questions or doubts in the question.

In stage IV, the questions that remained on the instrument (46 questions) underwent a face and content validation, reviewed by 4 expert researchers in the areas of physical exercise, sports training, and scientific research methodology. The last step involved the analysis of the instrument psychometric properties $(n=333)[10]$. 
The questionnaire consists of 46 close-ended multiple-choice questions, related to the methodology and structure of exercise training and organized in the following aspects: muscle strength, cardiorespiratory fitness and flexibility. The questions address aspects related to the training volume and intensity variables, in addition to other issues related to the training structure, such as diagnosis, programming, evaluation and control of these variables. Thus, questions 1 to 23 and 27 to 36 are related to the training methodology, and the remaining questions, 24 to 26 and 37 to 46, refer to the structuring of the training (available on: https://www.researchgate.net/publication/357280777_Methodology_of_ physical_exercise_A_proposal_and_reliability_of_a_questionnaire_for_fitness_professionals).

The sample size considered the probability of type I errors of $5 \%$, a power of $80 \%$, number of items 6, expected Cronbach's alpha of 0.7, and the null hypothesis 0.5 , resulting in 78 participants.

Participants were instructed to answer all the questions, choosing only one of the alternatives and, if in doubt, choosing the alternative "I prefer not to answer." No clarifications were provided regarding the interpretation of the questions, to avoid induction of the answers. After seven days, the questionnaire was reapplied. The interviews took place at scheduled times.

\section{STATISTICAL ANALYSIS}

Cronbach's alpha and its respective 95\% confidence intervals $(95 \% \mathrm{CI})$ were calculated to verify the internal consistency of the ordinal categorical variables of the participants in the pre-test, and the alpha values (95\%CI) if an item were deleted. For nominal variables, the phi $(2 \times 2$ contingency tables) and Cramer's V (contingency tables greater than $2 \times 2)$ were used as effect size measures, and the $95 \%$ CI was calculated by the Bootstrap method (number of samples $=1000$ ). The phi coefficient and Cramer's V correlation interpretation were realized with the following categories: 0.0 to 0.05 : no or very weak; $>0.05$ to 0.10 : weak; $>0.10$ to 0.15 : moderate; $>0.15$ to 0.25 : strong; $>0.25$ : very strong [11]. The kappa index was used to verify the agreement between the test and retest. Kappa values with linear weighting were presented, as well as the percentage agreement (\%), with their respective confidence intervals $(95 \% \mathrm{CI})$ for each of the questions. The data were classified as follows: $<0.20$ : poor; 0.21 to 0.40 : fair; 0.41 to 0.60 : moderate; 0.61 to 0.80 : good; 0.81 to 1.0 : very good [12]. The level of significance in this study was set at $\mathrm{P}<0.05$. All statistical analyses were conducted using the software IBM SPSS Statistics for Windows, version 20 (IBM Corp., Armonk, N.Y., USA).

\section{INFORMED CONSENT}

Informed consent has been obtained from all individuals included in this study.

\section{ETHICAL APPROVAL}

The research related to human use has complied with all the relevant national regulations and institutional policies; it has followed the tenets of the Declaration of Helsinki and has been approved by the research ethics committee of University Center Philadelphia - UNIFIl (n.1.013.727).

\section{RESULTS}

The overall value of Cronbach's alpha $(\mathrm{n}=333$ ) was 0.80 (95\%CI: $0.61-0.82)$. The values for each question if the item was deleted ranged from 0.78 to 0.80 (Table 1 ). The mean value for the effect size measures (Phi/Cramer's V) was 0.16 ( \pm 0.06$)$, with $7.7 \%$ classified as very weak to weak, $46.2 \%$ as moderate, $37.4 \%$ as strong, and $8.8 \%$ as very strong (Table 2 ). 
Table 1. Cronbach's alpha values and confidence interval (95\% CI)

\begin{tabular}{cccc}
\hline Question & $\alpha$ Cronbach $(95 \% \mathrm{Cl})^{*}$ & Question & $\alpha$ Cronbach $(95 \% \mathrm{Cl})^{*}$ \\
\hline 1 & $0.791(0.756-0.821)$ & 17 & $0.791(0.756-0.821)$ \\
2 & $0.789(0.754-0.819)$ & 18 & $0.796(0.762-0.825)$ \\
3 & $0.788(0.753-0.818)$ & 19 & $0.795(0.761-0.824)$ \\
4 & $0.783(0.747-0.814)$ & 20 & $0.785(0.749-0.816)$ \\
5 & $0.795(0.761-0.824)$ & 21 & $0.794(0.760-0.824)$ \\
6 & $0.792(0.757-0.822)$ & 22 & $0.792(0.757-0.822)$ \\
7 & $0.790(0.756-0.821)$ & 23 & $0.791(0.756-0.821)$ \\
8 & $0.787(0.751-0.818)$ & 27 & $0.783(0.747-0.814)$ \\
9 & $0.791(0.756-0.821)$ & 28 & $0.792(0.757-0.822)$ \\
10 & $0.796(0.762-0.825)$ & 29 & $0.781(0.744-0.812)$ \\
11 & $0.789(0.754-0.819)$ & 30 & $0.796(0.762-0.825)$ \\
12 & $0.784(0.748-0.815)$ & 38 & $0.792(0.757-0.822)$ \\
13 & $0.795(0.761-0.824)$ & 39 & $0.787(0.751-0.818)$ \\
14 & $0.796(0.762-0.825)$ & 40 & $0.787(0.751-0.818)$ \\
15 & $0.792(0.757-0.822)$ & 41 & $0.785(0.749-0.816)$ \\
16 & $0.792(0.757-0.822)$ & 42 & $0.786(0.750-0.817)$ \\
\hline
\end{tabular}

* Cronbach's alpha if item deleted refers to pretest $(n=333)$. No values of $p<0.05$ were observed.

Table 2. V-Cramer values and confidence interval (95\% CI)

\begin{tabular}{|c|c|c|c|c|c|}
\hline Question & $\begin{array}{l}\text { V-Cramer } \\
(95 \% \mathrm{Cl})\end{array}$ & Question & $\begin{array}{l}\text { V-Cramer } \\
(95 \% \mathrm{Cl})\end{array}$ & Question & $\begin{array}{l}\text { V-Cramer } \\
(95 \% \mathrm{Cl})\end{array}$ \\
\hline 24 vs. 25 & $0.31(0.15-0.47)$ & 26 vs. 36 & $0.13(0.13-0.23)$ & 33 vs. 45 & $0.11(0.10-0.23)$ \\
\hline 24 vs. 26 & $0.30(0.23-0.50)$ & 26 vs. 37 & $0.09(0.09-0.18)$ & 33 vs. 46 & $0.15(0.14-0.23)$ \\
\hline 24 vs. 31 & $0.14(0.12-0.25)$ & 26 vs. 43 & $0.15(0.11-0.25)$ & 34 vs. 35 & $0.14(0.14-0.27)$ \\
\hline 24 vs. 32 & $0.14(0.12-0.27)$ & 26 vs. 44 & $0.19(0.11-0.30)$ & 34 vs. 36 & $0.18(0.13-0.33)$ \\
\hline 24 vs. 33 & $0.20(0.13-0.45)$ & 26 vs. 45 & $0.12(0.12-0.22)$ & 34 vs. 37 & $0.14(0.13-0.24)$ \\
\hline 24 vs. 34 & $0.15(0.11-0.31)$ & 26 vs. 46 & $0.18(0.17-0.28)$ & 34 vs. 43 & $0.17(0.10-0.28)$ \\
\hline 24 vs. 35 & $0.20(0.15-0.40)$ & 31 vs. 32 & $0.18(0.16-0.30)$ & 34 vs. 44 & $0.15(0.09-0.27)$ \\
\hline 24 vs. 36 & $0.17(0.12-0.36)$ & 31 vs. 33 & $0.18(0.14-0.35)$ & 34 vs. 45 & $0.14(0.14-0.23)$ \\
\hline 24 vs. 37 & $0.13(0.11-0.25)$ & 31 vs. 34 & $0.13(0.12-0.25)$ & 34 vs. 46 & $0.15(0.14-0.25)$ \\
\hline 24 vs. 43 & $0.14(0.10-0.24)$ & 31 vs. 35 & $0.23(0.20-0.34)$ & 35 vs. 36 & $0.14(0.13-0.29)$ \\
\hline 24 vs. 44 & $0.10(0.07-0.23)$ & 31 vs. 36 & $0.14(0.14-0.24)$ & 35 vs. 37 & $0.13(0.12-0.21)$ \\
\hline 24 vs. 45 & $0.12(0.12-0.22)$ & 31 vs. 37 & $0.15(0.13-0.27)$ & 35 vs. 43 & $0.14(0.09-0.27)$ \\
\hline 24 vs. 46 & $0.12(0.12-0.20)$ & 31 vs. 43 & $0.10(0.08-0.23)$ & 35 vs. 44 & $0.11(0.08-0.24)$ \\
\hline 25 vs. 26 & $0.19(0.15-0.31)$ & 31 vs. 44 & $0.07(0.06-0.21)$ & 35 vs. 45 & $0.17(0.16-0.28)$ \\
\hline 25 vs. 31 & $0.15(0.14-0.27)$ & 31 vs. 45 & $0.16(0.16-0.28)$ & 35 vs. 46 & $0.13(0.13-0.22)$ \\
\hline 25 vs. 32 & $0.27(0.19-0.38)$ & 31 vs. 46 & $0.12(0.12-0.21)$ & 36 vs. 37 & $0.12(0.12-0.21)$ \\
\hline 25 vs. 33 & $0.27(0.12-0.43)$ & 32 vs. 33 & $0.27(0.22-0.44)$ & 36 vs. 43 & $0.14(0.09-0.27)$ \\
\hline 25 vs. 34 & $0.19(0.16-0.30)$ & 32 vs. 34 & $0.16(0.14-0.29)$ & 36 vs. 44 & $0.10(0.07-0.23)$ \\
\hline 25 vs. 35 & $0.17(0.15-0.32)$ & 32 vs. 35 & $0.20(0.16-0.33)$ & 36 vs. 45 & $0.14(0.14-0.38)$ \\
\hline 25 vs. 36 & $0.17(0.15-0.31)$ & 32 vs. 36 & $0.25(0.20-0.36)$ & 36 vs. 46 & $0.13(0.13-0.23)$ \\
\hline 25 vs. 37 & $0.14(0.13-0.22)$ & 32 vs. 37 & $0.14(0.14-0.26)$ & 37 vs. 43 & $0.11(0.08-0.24)$ \\
\hline 25 vs. 43 & $0.19(0.12-0.30)$ & 32 vs. 43 & $0.13(0.08-0.24)$ & 37 vs. 44 & $0.14(0.09-0.27)$ \\
\hline 25 vs. 44 & $0.08(0.08-0.21)$ & 32 vs. 44 & $0.09(0.07-0.20)$ & 37 vs. 45 & $0.14(0.14-0.22)$ \\
\hline 25 vs. 45 & $0.17(0.16-0.30)$ & 32 vs. 45 & $0.16(0.15-0.28)$ & 37 vs. 46 & $0.13(0.13-0.21)$ \\
\hline 25 vs. 46 & $0.16(0.16-0.24)$ & 32 vs. 46 & $0.16(0.14-0.26)$ & 43 vs. 44 & $0.40(0.32-0.47)^{*}$ \\
\hline
\end{tabular}




\begin{tabular}{cccccc} 
Question & $\begin{array}{c}\text { V-Cramer } \\
(95 \% \mathrm{Cl})\end{array}$ & Question & $\begin{array}{c}\text { V-Cramer } \\
(95 \% \mathrm{Cl})\end{array}$ & Question & $\begin{array}{c}\text { V-Cramer } \\
(95 \% \mathrm{Cl})\end{array}$ \\
\hline 26 vs. 31 & $0.15(0.13-0.26)$ & 33 vs. 34 & $0.18(0.14-0.32)$ & 43 vs. 45 & $0.15(0.10-0.24)$ \\
26 vs. 32 & $0.15(0.14-0.28)$ & 33 vs. 35 & $0.24(0.18-0.41)$ & 43 vs. 46 & $0.29(0.20-0.40)$ \\
26 vs. 33 & $0.15(0.13-0.24)$ & 33 vs. 36 & $0.16(0.13-0.34)$ & 44 vs. 45 & $0.22(0.15-0.35)$ \\
26 vs. 34 & $0.19(0.12-0.25)$ & 33 vs. 37 & $0.12(0.11-0.21)$ & 44 vs. 46 & $0.20(0.13-0.32)$ \\
26 vs. 35 & $0.17(0.14-0.27)$ & 33 vs. 43 & $0.17(0.11-0.25)$ & 45 vs. 46 & $0.28(0.25-0.36)$ \\
& & 33 vs. 44 & $0.04(0.04-0.18)$ & & \\
\hline
\end{tabular}

* Phi coefficient

Table 3 presents the kappa index values for all questions. A total of $15.2 \%$ of the questions were classified as presenting regular agreement, $71.7 \%$ moderate agreement, and $13.0 \%$ good agreement. For kappa with linear weighting, the values were $13.0 \%, 56.5 \%$, and $30.4 \%$, respectively. Percentage agreement values ranged from 48.8\% (95\%CI: 37.8-59.8) to $90.3 \%$ (95\%CI: 81.3-95.4).

Table 3. Kappa index and percentage agreement values (\%) between test and retest

\begin{tabular}{|c|c|c|c|c|c|c|c|}
\hline Question (n) & Kappa & K Linear & $\%(95 \% \mathrm{Cl})$ & Question (n) & Kappa & K Linear & $\%(95 \% \mathrm{Cl})$ \\
\hline $1(84)$ & 0.33 & 0.38 & $71.4(60.4-80.5)$ & $24(84)$ & 0.60 & 0.70 & $72.6(61.6-81.5)$ \\
\hline $2(83)$ & 0.46 & 0.50 & $67.5(56.1-77.1)$ & $25(83)$ & 0.66 & 0.67 & $78.3(67.6-86.3)$ \\
\hline $3(84)$ & 0.57 & 0.62 & $78.6(68.0-84.6)$ & $26(82)$ & 0.49 & 0.58 & $65.8(54.4-75.7)$ \\
\hline $4(81)$ & 0.55 & 0.60 & $65.4(54.0-75.4)$ & $27(84)$ & 0.44 & 0.50 & $62.0(50.6-72.0)$ \\
\hline $5(84)$ & 0.54 & 0.55 & $72.6(61.6-81.5)$ & $28(80)$ & 0.37 & 0.54 & $53.7(42.3-64.8)$ \\
\hline $6(84)$ & 0.41 & 0.54 & $60.7(49.4-71.0)$ & $29(84)$ & 0.45 & 0.41 & $58.3(47.0-68.8)$ \\
\hline 7 (83) & 0.38 & 0.53 & $57.8(46.5-68.4)$ & $30(84)$ & 0.32 & 0.42 & $54.7(43.5-65.5)$ \\
\hline $8(83)$ & 0.44 & 0.53 & $62.6(51.3-72.8)$ & 31 (84) & 0.53 & 0.54 & $81.0(70.6-88.4)$ \\
\hline $9(83)$ & 0.38 & 0.40 & $60.2(48.8-70.6)$ & $32(84)$ & 0.56 & 0.51 & $77.3(66.7-85.5)$ \\
\hline $10(84)$ & 0.57 & 0.63 & $73.8(62.8-82.5)$ & $33(84)$ & 0.49 & 0.39 & $84.5(74.6-91.1)$ \\
\hline $11(83)$ & 0.42 & 0.55 & $53.0(41.8-63.9)$ & $34(84)$ & 0.67 & 0.73 & $81.0(70.6-88.4)$ \\
\hline $12(84)$ & 0.36 & 0.45 & $56.0(44.7-66.6)$ & $35(83)$ & 0.55 & 0.35 & $69.8(58.6-79.2)$ \\
\hline $13(83)$ & 0.60 & 0.72 & $79.5(68.9-87.2)$ & $36(84)$ & 0.59 & 0.61 & $69.0(57.8-78.4)$ \\
\hline $14(84)$ & 0.60 & 0.65 & $77.3(66.7-85.5)$ & $37(84)$ & 0.50 & 0.61 & $66.6(55.4-76.3)$ \\
\hline $15(84)$ & 0.48 & 0.56 & $59.5(48.2-69.9)$ & $38(84)$ & 0.63 & 0.68 & $76.1(65.4-84.5)$ \\
\hline $16(83)$ & 0.46 & 0.53 & $60.2(48.8-70.6)$ & $39(82)$ & 0.66 & 0.65 & $75.6(64.6-84.1)$ \\
\hline $17(84)$ & 0.46 & 0.53 & $63.1(51.8-73.1)$ & $40(82)$ & 0.54 & 0.48 & $69.5(58.2-78.9)$ \\
\hline $18(83)$ & 0.43 & 0.54 & $56.6(45.3-67.3)$ & 41 (83) & 0.60 & 0.59 & $72.2(61.2-81.2)$ \\
\hline $19(84)$ & 0.41 & 0.53 & $56.0(44.7-66.6)$ & $42(82)$ & 0.41 & 0.36 & $58.5(47.2-69.1)$ \\
\hline $20(84)$ & 0.38 & 0.52 & $48.8(37.8-59.8)$ & $43(84)$ & 0.76 & 0.76 & $89.1(19.9-94.6)$ \\
\hline $21(84)$ & 0.50 & 0.59 & $61.7(49.3-71.0)$ & $44(83)$ & 0.75 & 0.75 & $90.3(81.3-95.4)$ \\
\hline $22(83)$ & 0.52 & 0.55 & $68.6(57.4-78.1)$ & $45(84)$ & 0.42 & 0.35 & $59.5(48.2-69.9)$ \\
\hline $23(84)$ & 0.42 & 0.54 & $57.1(45.8-67.7)$ & $46(84)$ & 0.54 & 0.62 & $63.1(51.8-73.1)$ \\
\hline
\end{tabular}

95\% Cl: 95\% confidence interval, $\mathrm{K}$ linear: Kappa linear

\section{DISCUSSION}

In the current study, the psychometric properties of a questionnaire on the methodology of physical exercise used by fitness professionals presented acceptable values. Cronbach's alpha if item deleted indicated that none of the questions had a negative influence on this coefficient. Reliability for the test and retest was between high and regular for all questions. 
The results confirm the effectiveness of questionnaires of this nature, due to the ease of applicability in large groups, considering the context in which the professional is inserted, and with a low cost. However, few studies have been performed on the methodology of physical exercise, making it difficult to compare results related to psychometric properties for the same issue. However, psychometric capacity can be comparatively analyzed in the light of information about other aspects related to health and fitness.

The Cronbach's alpha value corresponds to the recommendations of the specialized literature, with the lowest value found being 0.78. Usually, for an instrument to present acceptable internal consistency, the values of the questions should be at least 0.7 , as quoted by Nunnally \& Bersntein [13]. However, it should be pointed out that high alpha values are not expected for instruments with heterogeneous items, even if there are no measurement errors [14]. In addition, values from 0.6 can be acceptable with caution in cases where the questionnaire is designed to test a specific population $[15,16]$.

Heo et al. [17], in an instrument for nutritional assessment, observed alpha values below the recommended one for vegetable and fruit intake (0.61), food (0.52), intake of new fruits and vegetables (0.59), and milk and cereal intake (0.53). Investigating young Brazilian athletes (through a questionnaire on motivation) also maintained the "Fun" factor, which presented an alpha below the recommendation (0.54), considering it to be indispensable for understanding the researched phenomenon [18].

A similar decision was made by Mota, Matos, \& Lemos [19], and the size (affirmation) presented an alpha value of 0.55 , as well as by Rutkowski \& Connelly [20] with alpha values of parents and children on knowledge of risk factors related to obesity being 0.53 and 0.59 , respectively. Additionally, Choobineh, Ghaem, \& Ahmedinejad [21], whose objective was to translate a questionnaire that assesses stress in the workplace, maintained questions related to discretion ability and decision authority, despite the fact that they presented internal consistency values of 0.54 and 0.58 , respectively.

Regarding test-retest reliability, all questions generally presented acceptable values, with only $15.2 \%$ of the questions classified as regular (questions $1,7,9,12,20,28,30$ ). Question 1 in this case refers to the percentage of load used to develop the maximum force. However, contextual relevance should be considered for understanding the general phenomenon, besides which, the structure of the question is similar to questions 2,3 , and 4 , which presented moderate to good classifications.

Question 7 refers to the number of exercises per muscle group used to develop maximum strength. The updated literature is not specific as to the number of exercises to be adopted per muscle group, with the recommendations generally focusing on the total number of sets per muscle group, from 1 to 2 for global training and 3 to 4 for fractional training [5, $22,23]$ Questions 9 and 12 were also classified as regular and refer to the number of sets used to develop resistance strength and muscle power, respectively. These are related to the training volume and present small variation in the literature regarding prescription (between 1 and 2 sets) to develop resistance strength [24]. Despite the observed classification, $56 \%$ of professionals opted for the same alternative between the tests. The muscle power corresponding to sports performance is not widely considered by the participants of this study who aim at improving the health condition of practitioners and, therefore, it is possible that this is a determining factor for different choices regarding the number of sets between one test and another. Similarly, this would also justify the regular classification of question 20 regarding the recovery time used between sets to develop muscle power output. 
Question 28 addresses the average heart rate used to develop aerobic endurance. The use of the maximum $\mathrm{VO}_{z}$ percentage is recommended in the literature for the development of aerobic resistance $[5,25]$. However, in practice, the adoption of the absolute heart rate values is observed, as suggested by classical studies, such as those by Astrand \& Rodahl [26] and Zakharov \& Gomes [27] and justified by its easy applicability and control.

The fact that question 30, regarding the average aerobic activity time prescribed for fat loss, is classified as regular raises the question of the level of professionals' knowledge about the subject, since there are consistent recommendations in the scientific literature which indicate values between 250 to 300 minutes per week for this purpose [25].

When the question was classified as moderate by kappa and regular by linear kappa, there was a percentage agreement, ranging from $58.5 \%$ to $84.5 \%$. In addition, more than $50 \%$ of participants concentrated their answers between one or two alternatives (questions 33, 35, 42 , and 45 ). When the question was classified as moderate by linear kappa and regular by kappa, there was a lower percentage agreement (48.8\% to $57.8 \%$ ), and the answers were distributed among at least four alternatives (questions 7, 12, 20, 28, 30).

The use of instruments such as questionnaires with objective answers may limit understanding of the phenomenon as a whole, since it biases the delimitation of the answers. The fact that the interviewed professionals could not resort to specialized literature at any time may be a limitation of this study, since it does not fully represent the reality experienced by professionals, who often resort to consultations on websites or specialized literature when discussing and preparing exercise training programs.

Although sampling was for convenience, the sample size was adequate for the objectives established in this study. To date, there is no information on the potential influence of working time on methodological choices; however, the working time, as well as sociodemographic aspects of these professionals, such as age, sex, and even higher education institution may be related to the obtained results.

\section{CONCLUSION}

In general, the proposed instrument is a reliable way to verify the methodological approach used by the studied population. Physical exercise is widely used as an intervention strategy in health promotion and disease prevention programs. The application of this instrument by other researchers would enable identifying trends in methodologies used in different regions of the country. In addition, the instrument could help in the proposal of guidelines, as well as to verify the adherence of professionals to these recommendations.

\section{ACKNOWLEDGMENTS}

National Postdoctoral Program of CAPES (PNPD/CAPES) and Foundation for Science and Technology Support from Pernambuco (FACEPE).

\section{REFERENCES}

[1] PiercyKL, Troiano RP, Ballard RM, et al. The Physical Activity Guidelines for Americans. JAMA. 2018 Nov 20;320(19):2020-2028. https://doi.org/10.1001/jama.2018.14854

[2] Powell KE, King AC, Buchner DM, et al. The Scientific Foundation for the Physical Activity Guidelines for Americans, 2nd edition. J Phys Act Health. 2018; Dec 17:1-11. https://doi.org/10.1123/jpah.2018-0618

[3] Metcalf BS. Hosking J, Jeffery AN, et al. Exploring the Adolescent Fall in Physical Activity: A 10-yr Cohort Study (EarlyBird 41). Med Sci Sports Exerc. 2015;47(10):2084-92. https://doi.org/10.1249/MSS.0000000000000644

[4] Telama R, Yang X, Leskinen E, et al. Tracking of physical activity from early childhood through youth into adulthood. Med Sci Sports Exerc. 2014;46(5):955-62. https://doi.org/10.1249/MSS.0000000000000181 
[5] Garber CE, Blissmer B, Deschenes MR, et al. American College of Sports Medicine position stand. Quantity and quality of exercise for developing and maintaining cardiorespiratory, musculoskeletal, and neuromotor fitness in apparently healthy adults: guidance for prescribing exercise. Med Sci Sports Exerc. 2011;43(7):1334-59. https:// doi.org/10.1249/MSS.0b013e318213fefb

[6] Schoenfeld BJ, Wilson JM, Lowery RP, Krieger JW. Muscular adaptations in low-versus high-load resistance training: A meta-analysis, European Journal of Sport Science 2014;16(1):1-10. https://doi.org/10.1080/17461391.2014.989922

[7] Folland JP, Williams AG The adaptations to strength training: Morphological and neurological contributions to increased strength. Sports Med. 2007;37(2):145-68. https://doi.org/10.2165/00007256-200737020-00004

[8] Gomes I, Caminha I. Um olhar sobre a formação e atuação profissional no Brasil: o caso dos personaltrainers. Pensar a Prática. 2014;17(2). https://doi.org/10.5216/rpp.v17i2.25681

[9] US Department of Health Human Services. Physical Activity Guidelines for Americans. Department of Health and Human Services. 2nd, ed. Washington, DC, U.S; 2018.

[10] Babbie E. Método de Pesquisa survey. 2nd, UFMG, Belo Horizonte; 2003.

[11] Akoglu H. User's guide to correlation coefficients. Turk J Emerg Med. 2018;18(3):91-93. https://doi.org/10.1016/j. tjem.2018.08.001.

[12] Altman DG. Practical statistics for medical research. London: Chapman; 1991. https://doi.org/10.1201/9780429258589

[13] Nunnally JC, Bernstein IH. Psychometric theory. 3rd ed. New York: McGraw-Hill; 1994.

[14] Cronbach LJ. Coefficient alpha and internal structure of tests. Psychometrika. 1951;1:297-334. https://doi. org/10.1007/BF02310555

[15] Kottner J, Streiner DL. Internal consistency and Cronbach's $\alpha$ : A comment on Beeckman. Int J Nurs Stud. 2010;47:926928. https://doi.org/10.1016/j.ijnurstu.2009.12.018

[16] Streiner DL. Being inconsistent about consistency: when coefficient alpha does and doesn't matter J Personal Assess. 2003;80:217-222. https://doi.org/10.1207/S15327752JPA8003_01

[17] Heo M, Irvin E, Ostrovskyn N, et al. Behaviors and knowledge of health corps New York City school students: nutrition, mental health and physical activity. J School Health. 2016;86(2):84-95. https://doi.org/10.1111/josh.12355

[18] Guedes DP, Netto JES. Sport participation motives of Young Brazilian athletes. Percept Motor Skill: Exerc Sport. 2013;117(3):742-759. https://doi.org/10.2466/06.30.PMS.117x33z2

[19] Mota CP, Matos PM, Lemos MS. Psychometric Properties of the Social Skills Questionnaire: Portuguese Adaptation of the Students form (grades 7 to 12). Spanish J Psychol. 2011;14(1):456-499. https://doi.org/10.5209/rev SJOP.2011. v14.n1.44

[20] Rutkowski EM, Connelly CD. Obesity Risk Knowledge and Physical Activity in Families of Adolescents. J Pediatr Nurs. 2011;26:51-57. https://doi.org/10.1016/j.pedn.2009.12.069

[21] Choobineh A, Ghaem H, Ahmedinejad P. Validity and reliability of the Persian (Farsi) version of job Content Questionnaire: a study among hospital nurses. East Mediterr Health J. 2011;17(4):335-341. https://doi.org/10.26719/2011.17.4.335

[22] Kraemer WJ, Nindl BC, Ratamess NA, et al. Changes in muscle hypertrophy in women with periodized resistance training. Med Sci Sports Exerc. 2004;36(4):697-708. https://doi.org/10.1249/01.MSS.0000122734.25411.CF

[23] Ratamess NA, Alvar BA, Evetoch TK, et al. Progression Models in Resistance Training for Healthy Adults. Med Sci Sport Exerc. 2009;41(3):687-708. https://doi.org/10.1249/MSS.0b013e3181915670

[24] KRIEGER JW. Single vs. multiple sets of resistance exercise for muscle hypertrophy: a meta-analysis. J Strength Condition Res. 2010; 24; 4:1150-9 https://doi.org/ 10.1519/JSC.0b013e3181d4d436.

[25] Donnelly JE, Blair SN, Jakicic JM et al. Appropriate Physical Activity Intervention Strategies for Weight Loss and Prevention of Weight Regain for Adults. Med Sci Sport Exerc. 2009;41(2):459-71. https://doi.org/10.1249/ MSS.0b013e3181949333

[26] Astrand P, Rodahl K. Text book of work physiology. New York, McGraw-Hill; 1986.

[27] Zakharov A A, Gomes AC. Sports training Science [Port]. 2nd, Grupo Palestra Sport, Rio de Janeiro; 2003. 